\title{
Effectiveness of a pesticide protective behavior program in improving and reducing neuromuscular symptoms among rice farmers in Sukhothai province, Thailand
}

\author{
P. Markmee, S. Taneepanichskul \& R. S. Chapman \\ College of Public Health Sciences, Chulalongkorn University, Thailand
}

\begin{abstract}
The problem of inappropriate pesticide usage is an important concern for occupational authorities in Thailand. There have been few intervention studies aimed at improving protective behavior and reducing health risk. In this quasiexperimental study, we conducted a pesticide protective behavior intervention program. We assessed the effectiveness of this intervention in improving protective behavior, and reducing neuromuscular symptom prevalence, among 182 rice farmers from December 2011 to June 2012 in Sukhothai province, Thailand. The intervention group comprising 91 rice farmers received a 1-month intervention program. Outcomes were measured before intervention (baseline), and at 1 and 4 months after intervention. The effects of intervention were evaluated with difference-of-difference analysis. The result revealed that all the participants had retention all follow-up time. At baseline, the mean protective behavior score was 50.7 in both the groups. The intervention program improved the protective behavior by a mean score of $8.6(95 \%$ CI $7.4-9.9 ; p<0.001)$ one month after the intervention and by a mean score of 6.2 (95\%CI 3.9-8.5; $p<0.001) 4$ months later, and reduced the prevalence of neuromuscular symptoms by 30.3 percent-points $(95 \% \mathrm{CI}-42.5$ to -18.2 ; $p<0.001)$ one month after the intervention and by 31.0 percent-points $(95 \% \mathrm{CI}-47.4$ to $-\mathrm{t} 4.7$; $p<0.001) 4$ months after the intervention. Thus, this program should be considered for implementation to improve the safe use of pesticides in other
\end{abstract}


areas. Further studies on bio-monitoring should be implemented to test the effectiveness of the program for pesticides exposure.

Keywords: pesticides, protective behavior program, rice farmers, neuromuscular symptom, Thailand.

\section{Introduction}

Many pesticides are being imported into Thailand for use with commercial planting in agricultural farms, and are sold in market with more than 2000 brand names. However, two types of pesticides are widely used, namely insecticides (51\%) and herbicides (38\%), although since 1997, 82 kinds of pesticides have been banned in Thailand [1]. Use of pesticides is one of the methods that farmers employ to control pests. Pesticide usage has increased in Thailand. The agrochemical expenses in the years 2006, 2007, 2008, and 2009 were 10,530, $12,898,15,062$, and 19,181 million Baht per year, respectively. The volumes of agrochemical imports were as high as 75,473, 95,763, 116,322, and 109,907 tons per year, respectively [2]. Associations with cumulative exposure have been found to persist after excluding individuals who had a history of pesticide poisoning or had experienced an event involving high personal pesticide exposure. Self-reported neurologic symptoms have been observed to be associated with cumulative exposure to moderate levels of fumigants and organophosphate and organochlorine insecticides, regardless of recent exposure or history of poisoning [3]. Although the number of cases of pesticide poisoning in Thailand has decreased from 3109 to 1252 cases since 2000 to 2007, and increased again in 2008 by 1705 cases and in 2009 by 1691 cases, Sukhothai Province in northern Thailand has exhibited decreased incidence from 66 to 34 cases since 2005 to 2007, and increased incidence in 2008 (60 cases) [4]. Overall, the pesticides used were inappropriate, and the farmers failed to use suitable personal protection, apply pesticides in an appropriate fashion, or discard the waste safely. They frequently relied on commercial advertisements for the best pesticide to use [5], and the use of pesticide has been largely directed by self-behavior. In "political environment in which regulations do not cover how farmers apply pesticides, it is important to know what drives farmer's voluntary behavior of pesticide use" [6]. Prevalence of neuromuscular symptoms during or within $24 \mathrm{~h}$ of pesticide use among rice farmers was found to be $52.9 \%$, with the major symptom being exhaustion (35\%), and neuromuscular symptoms while mixing pesticide and after using them [7]. An earlier study on the influence of pesticide safety knowledge, beliefs, and intention found that knowledge levels were positively related to intentions, beliefs, and self-efficacy of use of personal protective gear, but were not significantly related to risk perceptions and peer norms concerning pesticide safety [8]. A review of the effectiveness of interventions to reduce pesticide overexposure and poisoning in worker populations found that most of the studies evaluated exposure at different configurations of PPE (personal protective equipment) or different mixing or handling methods. Majority of the studies were small field tests of protective equipment involving less than 20 workers. Some studies examined biological 
indices of exposure, such as cholinesterase or urinary metabolites, and PPE was found to be effective in reducing exposure. However, till date, no controlled studies have been carried out to address the issue of reducing pesticide poisonings [9]. Efforts have been taken to increase the awareness of the hazard of using pesticide substance, which exhibited little success. Nevertheless, awareness regarding use of good protection during pesticide application should be created through cooperation among rice farmers. The objective of the present study was to test the effects of pesticide risk reduction intervention program designed to increase protective behavior and reduce health risk of pesticide exposure.

\section{Methods}

\subsection{Participants}

This quasi-experiment was carried out from November 2011 to June 2012 at two of the 11 sub-districts of Kongkrailat, Sukhothai province, Thailand. The participants were 182 rice farmers (91 participants in the control group and 91 participants in the intervention group), 18-65 years of age, who employ pesticide application methods such as mixing, loading, spraying, and washing equipments at least once a year, work on rice farm at least once a year, and can read and write. Written informed consent was obtained from all the participants. The study protocol was approved by the ethical committee of Chulalongkorn University, Thailand.

\subsection{Procedures}

Two sub-districts were purposively selected for the intervention and control group. The distance between the intervention and control areas was about $6 \mathrm{~km}$, comprising both village and farm areas. Both the sub-districts had similar time period of growing rice farms. Evaluation was carried out during two-times follow-up at 1 month and 4 months after intervention. A previous study by Markmee and Chapman [7] was used as a basis for sample-size calculation. A total of 182 subjects were recruited to detect the outcome that might lose $10 \%$ follow up (91 subjects in the experimental group and 91 in the control group), appropriate for neuromuscular symptoms.

Pre-test: The intervention group comprised 91 randomly selected household participants from the 191 participants of all the 430 rice farmer households. The control group included randomly selected 91 household participants from the 165 participants of all the 255 rice farmer households. Questionnaires were developed from the studies by Sorat [10], Jariya [11], and the Agriculture Health Study of USA (AHS) [12]. Pilot test was used to achieve clarity of questionnaires. Cronbach's alpha protective behavior was 0.72. At a one-day conference, research assistants were hired and trained to administer the questionnaires (conduct questionnaire interviews). The participants were followup through cooperation with two health centers and health village volunteers in two sub-districts. 


\subsection{Pesticide protective behavior intervention program}

Pesticide protective behavior program was applied based on risk perception by Social Cognitive Psychological Model (CSPM) [13] and risk communication model [14], including 4-day program; 3 days of workshop, 1-day field application, and learning with colleague workers for four times. On the first day, the messages consisted of pesticide utilization and pesticide problems in Thailand ( $1 \mathrm{~h}$ ), pesticide data, protective behavior, and health risk data from data collection at the baseline data $(2 \mathrm{~h})$, classification and hazards of pesticides $(1 \mathrm{~h})$, and health risk (both acute and chronic health effects; 2 h). On the second day, the message consisted of pesticide information in the label $(1 \mathrm{~h})$, route of exposure $(1 \mathrm{~h})$, guideline for safe use of pesticides $(2 \mathrm{~h})$, and appropriate personal protective equipment ( $2 \mathrm{~h}$ ). On the third day, the messages comprised history of pesticide poisoning among participants and emergency first aid for pesticide injury or pesticide poisoning $(6 \mathrm{~h})$. This session comprised both demonstration and power point presentation of guidelines for emergency first aid for pesticide injuries or pesticide poisoning, followed by social learning and learning from previous experience of colleague workers. On the fourth day, field application of pesticides and group discussions about all activities in the field were carried out, and a summary of the entire program was provided (6 h). Field application aimed to demonstrate participants the advantage of the use of personal protective equipment when using pesticides and how to protect from the hazards when using pesticides. Learning with colleague workers (group learning for four times) was accomplished in villages by dividing the participants into six groups (15 participants per group). This session comprised social relations to improve social amplification and fright factors to behavioral expectation. The first session $(1.5 \mathrm{~h})$ comprised learning about the major behaviors of participants who had experienced pesticide-related health effects or pesticide poisoning, as well as addressing the questions of why and how to reduce the health risk of pesticide use. The second session $(1.5 \mathrm{~h})$ included learning about appropriate personal protective equipment. The third session (1.5 h) comprised learning about some protective behavior to reduce pesticides exposure. The fourth session $(1.5 \mathrm{~h})$ summarized the overall program and recommendation. The total duration of the program was $24 \mathrm{~h}$. Attendance evaluations of participants in each session were done by the researcher and research assistances. Materials included pesticide handbooks, posters, and power point presentation. Some activities were done during each day, developed by suggestion from expert from the ninth Bureau of Control and Prevention, Ministry of Public Health. Group discussion and conclusion of the program were implemented to make the participants clear about the program, and then explain the method of follow-up by the interviewer/administrator.

\subsection{Outcome and measurement}

The primary outcomes of the study were protective behavior and neuromuscular symptoms. The instrument for self-protective behavior was divided into three sections: (1) when mixing pesticide: five questions, including wearing plastic 
gloves, using mask, mixing as indicated on the labels, using stick to stir, and washing hand immediately after mixing, (2) when applying: 12 questions, including wearing a hat, using a mask to cover nose and mouth, wearing goggles, boots, plastic gloves, long-sleeves shirt, coverall, smoking cigarettes or chewing gums, drinking water or eating food, walking backward, and spraying only during the windless and less strong sunlight time, and (3) after using pesticides: six questions, including cleaning hands with soap immediately, changing clothes immediately, taking a bath immediately, washing work clothes separately from normal clothes, washing protective equipment after use, and cleaning equipment away from the source of utilized water. Self-protective behavior among rice farmers were divided into four parts and comprised a total of 23 questions concerning with their practicing in term of frequency of performing it. The range of possible scores was 0 through 69 points.

Neuromuscular symptoms (15 symptoms) were the self-reported symptoms that occurred at least once during or $24 \mathrm{~h}$ after using pesticides in the past week, including dizziness, headache, twitching eyelids, blurred vision, insomnia, staggering gait, seizure, shaky heart (irregular rhythm), exhaustion, sweating, muscle weakness, tremor, muscle cramps, excessive salivation, and numbness.

\subsection{Statistical analysis}

Descriptive statistics, including frequencies and percentage, were used for sociodemographic factors, pesticide use behaviors, self-protective behaviors, and symptoms. Mean, Median, and Standard deviation (S.D.) of the scores were calculated for the sociodemographic, pesticide use behavior, protective behaviors, and symptoms.

Analysis: At baseline, to compare personal characteristics (independent variables) and the outcome of measurement (dependent variables) between the intervention and control groups, independent $t$-test was used to compare continuous data, and Chi-square test was used to compare categories data. Evaluation: The researcher assessed the effects of the intervention on pesticide use behaviors and symptoms at two time points: 1 month and 4 months after the intervention. The effect size of the intervention was measured with difference-ofdifference analysis using the equation:

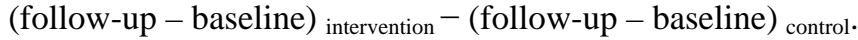

We used SPSS (version 17) to estimate the difference-of-difference effect sizes, the corresponding 95\% CIs and p-values, and employed the SPSS procedure with and identity link function and binomial distribution (dichotomous outcomes) so that the parameter estimates of the model were risk differences [15]. Some of these dependent variables were dichotomous and some were continuous. The dichotomous variables included presence/absence of symptoms, while continuous variables included overall scores for behaviors. The effects of intervention were evaluated with mixed multiple regression models that included variables for intervention status (group), time of study, and time-group interactions. The interactions provided the effects of specific tests of intervention at the respective data collection times after baseline. The models were adjusted for repeated within-subject measurements of outcomes at the respective data 
collection times. This adjustment was made for continuous outcomes with linear mixed models. For dichotomous outcomes, this adjustment was made with generalized estimating equations (GEE) applied to generalized linear models (distribution=binomial, link=identity). Regression models were adjusted for baseline characteristics that differed between the intervention and control groups, and for any other characteristics that were associated with the respective outcomes. For all the statistical tests used in this study, the level of significance (alpha) was 0.05.

\section{Results}

All the participants had retention. The demographic characteristics and pesticide use of the experimental and control groups are shown in Table 1 . The average age and farm size were similar in both the groups. The year of rice farmer, pesticide expended in last year, year of application of pesticides, number of days of pesticide use per year, and duration of each application showed statistically significant difference between the intervention and control groups. The year of rice farmers, year of application of pesticides, and duration of each application were higher in the control group. On the other hand, the average pesticides expended and number of days of pesticide use per year was higher in the intervention group. Chi-square test for categories data was used to compare the characteristics between the control and intervention groups.

Table 1: Demographic and pesticide use related characteristics by intervention status.

\begin{tabular}{|c|c|c|c|c|c|}
\hline \multirow[t]{2}{*}{ Characteristic } & \multicolumn{2}{|c|}{$\begin{array}{l}\text { Control } \\
(n=91)\end{array}$} & \multicolumn{2}{|c|}{$\begin{array}{c}\text { Intervention } \\
(n=91)\end{array}$} & \multirow[t]{2}{*}{$p$-value } \\
\hline & Mean & SD & Mean & SD & \\
\hline Age (years) & 46.0 & 10.1 & 43.2 & 11.9 & 0.095 \\
\hline Year of rice farmer & 28.5 & 12.1 & 18.2 & 11.8 & $<0.001$ \\
\hline Farm size (acre) & 13.5 & 7.1 & 15.4 & 11.2 & 0.171 \\
\hline $\begin{array}{l}\text { Pesticide expended in } \\
\text { last year (USD) } \\
\text { Years of application }\end{array}$ & 646.2 & 542.3 & 1242.1 & 1192.3 & $<0.001$ \\
\hline of pesticide & 21.1 & 8.3 & 11.9 & 8.4 & $<0.001$ \\
\hline $\begin{array}{l}\text { No. of days of } \\
\text { pesticide use per year }\end{array}$ & 18.7 & 18.1 & 54.8 & 60.1 & $<0.001$ \\
\hline $\begin{array}{l}\text { Duration of } \\
\text { each application (h) }\end{array}$ & 3.8 & 1.5 & 3.1 & 0.9 & $<0.001$ \\
\hline
\end{tabular}

In both the intervention and control groups, the majority were females. Gender, marital status, education, and family's monthly income had no statistically significant difference between the control and intervention groups. Both the groups had less than four household members. Most of the subjects in 
the intervention and control groups were married, and most of them had an education level of primary school or less. The frequency of cultivation showed a significant difference between the control and intervention groups. The control group had farmed three times higher than the intervention group. Most of the intervention and control groups had never been trained (95.6\%). All of them had the duty of handling, mixing, and spraying, and mixed more than three kinds of pesticides. The intervention group mixed pesticides at a level higher than the recommended one, as shown in Table 2.

Table 2: Demographic and pesticide use related characteristics by study group.

\begin{tabular}{|c|c|c|c|c|c|}
\hline \multirow[t]{2}{*}{ Characteristic } & \multicolumn{2}{|c|}{$\begin{array}{l}\text { Control } \\
(n=91)\end{array}$} & \multicolumn{2}{|c|}{$\begin{array}{l}\text { Intervention } \\
\quad(n=91)\end{array}$} & \multirow{2}{*}{$\begin{array}{c}p- \\
\text { value }\end{array}$} \\
\hline & $\boldsymbol{n}$ & $(\%)$ & $n$ & $(\%)$ & \\
\hline Male gender & 40 & $(44.0)$ & 45 & $(49.5)$ & 0.458 \\
\hline$>$ four household members & 23 & (25.3) & 38 & (41.8) & 0.019 \\
\hline Married & 82 & $(90.1)$ & 80 & (87.9) & 0.635 \\
\hline Secondary school or higher & 30 & $(33.0)$ & 27 & $(29.7)$ & 0.632 \\
\hline $\begin{array}{l}\text { Family monthly income } \\
<333.3 \text { USD }\end{array}$ & 49 & (53.8) & 38 & $(41.8)$ & 0.103 \\
\hline Cultivation three times per year & 42 & $(46.2)$ & 22 & $(24.2)$ & 0.002 \\
\hline Mix pesticide $>$ recommendation & 27 & $(29.7)$ & 43 & (47.3) & 0.015 \\
\hline
\end{tabular}

Pesticide use history in rice farms was divided into five classes, including herbicide, insecticide, fungicide, rodenticide, and other pesticides. The herbicides that were frequently used by subjects in the intervention and control groups, respectively, were as follows: 2-4D sodium salt (95.6 and 84.6\%), glyphosate (98.9 and 89.8\%), and butarchlor (87.9 and 70.3\%). Many of the insecticide family names were used in rice farms by both intervention and control groups. The most common insecticides used by both the groups were chlorpyrefos (control: $89.0 \%$ and intervention: 97.8\%) and abamectin (control: 98.9\% and intervention: 98.9\%). Most of them used insecticides by family names, such as organophosphate (OP) and carbamate groups. The most commonly used insecticide of the family carbamate was methomyl. There was no significant difference between the use of OP and carbamate insecticide family in both the groups. The most common fungicide used by both the intervention and control groups was propiconazole, and frequently used of fungicide was significantly different between the control and intervention groups, except for validamycin. The use of rodenticide, zinc phosphide, was higher in the intervention group (69.2\%) than the control group (34.1\%), and showed a significant difference between the groups. There were no significant differences with respect to bio-pesticide use between the intervention and control groups, as shown in Table 3. 
Table 3: Pesticide use history by classification, chemical family name, and study group.

\begin{tabular}{|c|c|c|c|c|c|}
\hline \multirow[t]{2}{*}{$\begin{array}{l}\text { Pesticide classification/ } \\
\text { family name }\end{array}$} & \multicolumn{2}{|c|}{$\begin{array}{c}\text { Control } \\
(n=91)\end{array}$} & \multicolumn{2}{|c|}{$\begin{array}{c}\text { Intervention } \\
(n=91)\end{array}$} & \multirow[t]{2}{*}{$p$-value } \\
\hline & $n$ & $(\%)$ & $n$ & $(\%)$ & \\
\hline Any herbicides & 91 & $(100)$ & 91 & 100 & 1.000 \\
\hline \multicolumn{6}{|l|}{ Insecticides } \\
\hline Any organophosphate & 90 & 98.9 & 91 & 100 & 0.316 \\
\hline Any carbamate & 71 & 78.0 & 62 & 68.1 & 0.133 \\
\hline Cypermethrin pyrethroids & 24 & 26.4 & 71 & 78.0 & $<0.001$ \\
\hline Abamectin & 90 & 98.9 & 90 & 98.9 & 1.000 \\
\hline Any fungicides & 84 & 92.3 & 91 & 100 & 0.007 \\
\hline Any rodenticides & 36 & 39.6 & 65 & 71.4 & $<0.001$ \\
\hline \multicolumn{6}{|l|}{ Other pesticides } \\
\hline Saponin (bio-pesticide) & 14 & 15.4 & 19 & 20.9 & 0.336 \\
\hline
\end{tabular}

History of exposure to pesticides when using as well as exposure of arms and legs to pesticides had no significant difference between the control and intervention groups. The control group reported higher incidences of exposure of head and face to pesticides and inhalation than the intervention group. On the other hand, the intervention group reported higher exposure of feet and digestive system to pesticides. The control and intervention group exhibited significant difference with respect to exposure of feet, inhalation, and digestive exposure, as shown in Table 4.

Table 4: $\quad$ History of exposure of body when using pesticides by study group.

\begin{tabular}{lccccr}
\hline Part of body & \multicolumn{2}{c}{$\begin{array}{c}\text { Control } \\
(\mathbf{n = 9 1 )}\end{array}$} & \multicolumn{2}{c}{$\begin{array}{c}\text { Intervention } \\
(\boldsymbol{n}=\mathbf{9 1})\end{array}$} & \multirow{2}{*}{$\boldsymbol{p}$-value } \\
\cline { 2 - 5 } & $\boldsymbol{n}$ & $\mathbf{( \% )}$ & $\boldsymbol{n}$ & $\mathbf{( \% )}$ & \\
\hline Head and face & 66 & 72.5 & 53 & 58.2 & 0.043 \\
Arms & 70 & 76.9 & 74 & 81.3 & 0.466 \\
Legs & 62 & 68.1 & 68 & 74.7 & 0.325 \\
Feet & 49 & 53.8 & 73 & 80.2 & $<0.001$ \\
Inhalation & 69 & 75.8 & 49 & 53.8 & 0.002 \\
Digestive & 8 & 8.8 & 37 & 40.7 & $<0.001$ \\
\hline
\end{tabular}

At baseline, the total scores exhibited no significant difference between the control and intervention groups. Prevalence of neuromuscular symptoms was higher in the intervention group at baseline, 1 month after intervention, and 4 months later. Otherwise, in intervention group, it had decreased at one month after intervention and 4 months later in Table 5. 
Table 5: $\quad$ Protective behavior mean score and prevalence of at least one neuromuscular symptom by intervention status and time.

\begin{tabular}{|c|c|c|c|c|c|c|c|}
\hline \multirow{2}{*}{\multicolumn{2}{|c|}{$\begin{array}{l}\text { Protective behavior } \\
\text { Score/Neuromuscular } \\
\text { symptom }\end{array}$}} & \multicolumn{2}{|c|}{ Baseline } & \multicolumn{2}{|c|}{$\begin{array}{c}1 \text { month } \\
\text { after } \\
\text { the end of } \\
\text { intervention }\end{array}$} & \multicolumn{2}{|c|}{$\begin{array}{c}\begin{array}{c}\text { months } \\
\text { after } \\
\text { the end of } \\
\text { intervention }\end{array} \\
\end{array}$} \\
\hline & & $\begin{array}{c}\text { Control } \\
(n=91)\end{array}$ & $\begin{array}{c}\text { Inter } \\
\text { vention } \\
(n=91)\end{array}$ & $\begin{array}{c}\text { Control } \\
(n=91)\end{array}$ & $\begin{array}{c}\begin{array}{c}\text { Inter } \\
\text { vention } \\
(n=91)\end{array} \\
\end{array}$ & $\begin{array}{c}\text { Control } \\
(n=91)\end{array}$ & $\begin{array}{c}\text { Inter } \\
\text { vention } \\
(n=91)\end{array}$ \\
\hline \multicolumn{8}{|c|}{ Protective behavior score } \\
\hline \multirow[t]{2}{*}{ Total score } & Mean & 50.7 & 50.7 & 51.1 & 59.8 & 54.3 & 59.5 \\
\hline & SD & 5.9 & 6.5 & 5.7 & 3.0 & 5.8 & 3.5 \\
\hline $\begin{array}{l}\text { At least one } \\
\text { neuromuscular } \\
\text { symptom }\end{array}$ & $n$ & 35 & 71 & 44 & $\begin{array}{c}49 \\
(53.8)\end{array}$ & $\begin{array}{c}37 \\
(40.7)\end{array}$ & $\begin{array}{c}45 \\
(49.5)\end{array}$ \\
\hline
\end{tabular}

Table 6: $\quad$ Effect size of practice mean score by intervention status and time.

\begin{tabular}{|c|c|c|c|c|}
\hline \multirow{3}{*}{$\begin{array}{l}\text { Protective } \\
\text { behavior } \\
\text { (score) }\end{array}$} & \multicolumn{4}{|c|}{ Intervention effect adjusted for confounding factors } \\
\hline & \multicolumn{2}{|c|}{$\begin{array}{l}1 \text { month after } \\
\text { end of intervention }\end{array}$} & \multicolumn{2}{|c|}{$\begin{array}{c}4 \text { months after } \\
\text { end of intervention }\end{array}$} \\
\hline & $\begin{array}{c}\text { Mean } \\
\text { change } \\
(95 \% \mathrm{CI})\end{array}$ & $p$-value & $\begin{array}{c}\text { Mean } \\
\text { change } \\
(95 \% \mathrm{CI})\end{array}$ & $p$-value \\
\hline \multirow{2}{*}{$\begin{array}{l}\text { Total } \\
\text { practice }\end{array}$} & 8.6 & & 6.2 & \\
\hline & $(7.4-9.9)$ & $<0.001$ & $(3.9-8.5)$ & $<0.001$ \\
\hline
\end{tabular}

General linear mixed model, adjusted repeated measure time, number of days of pesticide use, pesticide expend, household member, fungicide use, rodenticide use, history of exposure of head, feet, inhalation, and digestive exposure.

General linear model repeated measure ANOVA was used to test the overall effectiveness of the program by group activities. It was found that the intervention program had accomplished the practice of wearing plastic gloves during mixing of pesticides and washing hands immediately after mixing. In addition, the intervention program made the farmers to wear hat, use mask, wear goggles, wear boots, and wear plastic gloves during application of pesticides. With regard to practices after application of pesticides, the intervention program was effective in making the farmers clean spray equipments away from the source of utilized water. After adjusting for repeated measure time and confounding factors by general linear mixed model, it was found that the intervention program had greatly improved the protective behavior score when mixing at one month after intervention, when applying, after using and total 
protective behavior in both measurement times accept practice when mixing at four months after end of intervention, as shown in Table 6. When adjusted for repeated measure time and most recent exposure to pesticides by generalized estimated equation, the intervention program was observed to have reduced neuromuscular symptoms, as shown in Table 7.

Table 7: $\quad$ Effect size of at least one neuromuscular symptom by intervention status and time.

\begin{tabular}{|c|c|c|c|c|}
\hline \multirow{3}{*}{ Symptoms } & \multicolumn{4}{|c|}{ Intervention effect adjusted for confounding factors } \\
\hline & $\begin{array}{l}1 \text { montl } \\
\text { end of inte }\end{array}$ & $\begin{array}{l}\text { ter } \\
\text { ention }\end{array}$ & $\begin{array}{r}4 \text { mont } \\
\text { end of int }\end{array}$ & $\begin{array}{l}\text { Ifter } \\
\text { ention }\end{array}$ \\
\hline & $\begin{array}{l}\text { \% change } \\
(95 \% \mathrm{CI})\end{array}$ & $p$-value & $\begin{array}{l}\text { \% change } \\
(95 \% \mathrm{CI})\end{array}$ & p-value \\
\hline Neuromuscular & -30.3 & & -31.0 & \\
\hline symptoms & $\begin{array}{c}(-42.5 \text { to } \\
-18.2)\end{array}$ & $<0.001$ & $\begin{array}{c}(-47.4 \text { to } \\
-14.7)\end{array}$ & $<0.001$ \\
\hline
\end{tabular}

\section{Discussion and conclusion}

The findings of this study show that pesticide protective behavior program was effective in improving the protective behavior score of pesticide use by rice farmers both 1 month and 4 months after the intervention, except for practice when mixing 4 months after intervention. Some practices in the intervention group were improved in both the measurement times, such as use of mask and gloves when mixing, use of mask, goggles, gloves and wearing hat when applying pesticides. On the other hand, some practices showed less improvement, such as use of coverall and walking backward when spraying. Overall, the intervention program used more activities of risk communication [14].

The messages of the intervention program were particularly designed by the researchers using some of the data from baseline to formative self or cultural background [13] in the intervention area, such as pesticides class, family name, and history of pesticide poisoning. The messengers were supported by health workers in Kongkrailat public health office, Kongkrailat hospital, and the ninth Bureau of Control and Prevention, Phitsanuloke Province, Ministry of Public Health. Materials included pesticide handbooks, posters, and power point presentation. Field application and learning with colleague workers were implemented, which were different from those employed in other studies. The time period of rice farming was about 105 days. The highest frequency of cultivation was three times per year. Thus, periods of 1 month and 4 months 
were appropriate to test the effectiveness of the program. Similarly, the time of farming was the first criteria for selected groups of participants.

Self-reported symptoms were measured neuromuscular symptoms that occurred during or $24 \mathrm{~h}$ after using pesticides. The participants were trained before collecting data to make sure that the symptoms were from pesticides use. Prevalence of neuromuscular symptoms was higher in the intervention group at baseline. It was found that the number of days of pesticides use was higher in the intervention group than the control. The number of days of pesticides use was associated with the symptoms [3, 7], while the most recent exposure to pesticides had a strong association with intervention status, measurement time, and symptoms [3, 7]. As recall bias might occur for long period of measurement, the researcher used symptoms reported in the past week. After adjusting the most recent exposure by 7 days, it was found that the intervention program was effective in reducing the prevalence of symptoms both 1 month and 4 months after the intervention. At baseline time, there was the large difference in symptom prevalence between the control and intervention groups. This large difference lends uncertainty to interpretation of the symptom-relate results. The fully adjusted generalized estimating equation (GEE) models did not run, and the results present here for symptoms are only partially adjusted.

Thus, this intervention program should be implemented in other rice farm areas. The success of this program depends on the risk communication factors, including audiences, messages, medium, and messengers. In addition, further studies testing the effectiveness of the intervention programs should evaluate pesticides exposure by bio-monitoring to confirm that they reduce the pesticides exposure.

\section{References}

[1] Integrated Pest Management [IPM]. Integrated Pest Management.Reducing the risk. Retrieved Sept 4, 2005 from http://www.Ipmthailand.org/en/ Pesticides/risk_redyctuib.htm

[2] Department of Agriculture. Agrochemical imports online, http://as.doa.go.th/ard/stat2

[3] Kammel, F., Engel, L.S., Gladen, B.C., Hoppin, J.A., Alavanja, M.R., Sandler, D.P. Neurologic symptoms in licensed private pesticide applicators in the agricultural health study. Environ Health Perspect. 113, 7, 877-82, 2005.

[4] Bureau of Epidemiology, Ministry of Public Health, http://epid.moph.go.th/

[5] Plianbangchang, P., Jetiyanon, K., Wittaya-areekul, S. Pesticide use patterns among small-scale farmers: A case study from phitsanulok, Thailand. Southeast Asian Journal of Tropical Medicine and Public Health, 40, pp. 401- 410, 2009.

[6] Lichtenberg E., Zimmerman R. Adverse Health Experience, Environmental. Attitudes and Pesticide Usage Behavior of Farm Operators. Risk Analysis, 19, pp. 283-294, 1999. 
[7] Markmee P. and Chapman R.S. Factors influencing pesticide userelated symptoms among rice farmers in Sukhothai province, Thailand. $J$ health Res, 24 (suppl), pp. 13-20, 2010.

[8] Perry MJ, Marbella A, Layde P.M. Association of pesticide safety knowledge with beliefs and intentions among pesticide applicators. $J$ Occup Environ Med, 42, pp. 187-93, 2000.

[9] Keifer MC. Effectiveness of interventions in reducing pesticide overexposure and poisonings. Am J Prev Med, 18, pp. 80-9, 2000.

[10] Sorat W., The relationship between health belief, pesticide use and safety behaviors with acute poisoning symptom of farmers, Chaiyaphom Province. Master's Thesis, Faculty of Graduate Studied, Mahidol University, pp. 73-76, 2004.

[11] Jariya W. Effectiveness of participatory learning program on pesticide utilization among agriculturists in Srinakorn district, Sukhothai province. Master's Thesis of College of Public Health Sciences, Chulalongkorn University, pp. 97-105, 2006.

[12] Agriculture Health Study. Full Text of Questionnaires online, http://aghealth.nci.nih.gov/questionnaires.html

[13] Langford IH; Day RJ; Georgiou S; Bateman IJ. A Cognitive Social Psychological Model for Predicting Individual Risk Perceptions and Preference. UK: CSERGE Working Paper GEC 2000-09, 2000.

[14] Rohrmann, B., A socio-Psychological Model for Analyzing Risk Communication Process. The Australasian Journal of Disaster, 2, 1992, http://www.massey.ac.nz/ truma/issues/200-2/rohrmann.html

[15] Spiegelman D, Hertzmark E. Easy SAS calculations for risk or prevalence ratios and difference. Am J Epidemiol, 162, pp. 199-200, 2005. 